\title{
A study on common factors between critical thinking and religious education
}

\author{
Anita Homayoonfard ${ }^{\mathrm{a}^{*}}$ and Seyyed Mahdi Sajjadi ${ }^{\mathrm{b}}$
}

\begin{abstract}
${ }^{a}$ Master in History and Philosophy of Education Department of Islamic Education ,Tarbiat Modares University, Tehran, Iran, Member of Iranian Management System Company (SAMA)

${ }^{b}$ Associate professor of the philosophy of education, Tarbiat Modares University, Tehran, Iran

\section{A R T I C L E I N F O}

Article history:

Received March 15, 2012

Received in Revised form

March, 15, 2012

Accepted 18 May 2012

Available online

May 212012

Keywords:

Critical thinking

Religious education

Common factors

Critical thinking (CT) has been one of the most popular interests among many scholars, educators, and others who are concerned with thinking skills. There are many evidences to believe that critical thinking skills can lead to more prepared, productive and employable of interest in different countries. When the rules and regulations in a country are based on religious, it is necessary to use religious educational systems as part of regular teaching education. However, there are common factors between CT and religious education and we can and existing common factors between CT and religious educations. We explain that a hybrid of CT and religious education helps people search for truth, gives precise vision, helps use judgment and work harder.
\end{abstract}

\section{Introduction}

Critical thinking (CT) has been one of the most popular subjects of research among many people from different areas including scholars, educators, and others who are concerned with thinking skills (Çimer \& Timuçin, 2010). There are many evidences to believe that critical thinking skills can lead to more prepared, productive and employable students in the workforce. On the other hand, religious educations have been increasing subject of interest in different countries.

During the past few years, there have been tremendous efforts on CT and its advantages and there are many studies to measure the effects of CT on educational programs. Ku (2009) investigated the features and concerns of commonly adopted CT tests and its conceptualization. The study argued that CT tests utilizing a single multiple-choice response format measures only recognition or level of knowledge, and do not adequately capture the dispositional characteristics of test-takers.

\footnotetext{
* Corresponding author. Tel: +989122115338

E-mail addresses: anitahomayoonfard@yahoo.com (A. Homayoonfard)

(c) 2012 Growing Science Ltd. All rights reserved. 


\section{The role of critical thinking}

When CT is implemented properly, there are literally different advantages to increase learning in educational schools and there are literally many studies associated with them. Glassner and Schwarz (2007) explained that creative and CT had been conventionally considered as involving independent skills and dispositions. They performed some experimental studies, which was focused on relationship between creative and CT. The study demonstrated rich bonds between CT and antilogos evaluation and between their developments. They reported that to free themselves from holding one meaning, adolescents are required a high level of a specific aspect of CT, which would not develop during adolescence. The study also indicated that efficient antilogos evaluation involves both critical and creative thinking.

There are literally many different techniques for measuring CT and the Halpern CT assessment (HCTA) has been considered as one of the reliable measures of CT, which has been validated with numerous qualitatively various samples and measures of academic success. Butler et al. (2012) presented different cross-national applications of the assessment, and recent work to expand the validation of the HCTA with real-world outcomes of CT. The real-world outcomes (RWO) inventory studies behavior in a wide range of domains, such as education, health, finance, and interpersonal relationships and they investigated whether scores on the HCTA forecasted real-world outcomes in three qualitatively various samples in the United States. They also implemented the HCTA to evaluate the efficiency of an online CT course, and whether the HCTA forecasted real-world outcomes in Ireland. The third described preliminary study involving the translation quality of the RWO and explored differences in behaviors in the two countries. In summary, they confirmed that HCTA is a good technique for evaluating CT and predicts real-world outcomes of CT.

Marin and Halpern (2011) discussed that despite the fact that the development and transfer of CT skills are primary goals for education, there are few studies, which help educators decide how to teach in ways, which enhance CT. In two studies, they compared explicit and imbedded instructional modes and evaluated CT with the HCTA, which collects both constructed response and multiplechoice response formats with everyday situations. They study was performed among high school students in the United States attending low-performing high schools with large minority enrollment. They reported that grade point average was substantially associated with CT scores, but as expected its relationship with CT was much weaker than standardized test scores. They reported that explicit instruction is an efficient method for teaching CT skills to high school students.

Renaud and Murray (2008) in a comprehensive study compared two methods of subject-specific and general measure of CT. They provided a direct, controlled comparison between general and subjectspecific test questions in the context of a laboratory-based true experiment evaluating the impact of higher order review questions on gains in CT. They reported a stronger impact when the experiments of CT contained questions, which were subject-specific rather than questions, which focused on general topics.

Stapleton (2011) performed a survey of attitudes towards CT among Hong Kong secondary school teachers and reported that the teachers had a wide range of conceptions about its meaning and while some of them thought CT included only cognitive skill elements, the others thought CT incorporated only cognitive skill elements and another groups thought it was more dispositional in nature. Fung and Howe (2012) reported that the relevance of group work for fostering CT, looking in particular at the participation of teachers in small group activity. They paid more attention to the results of CT tests and excerpts extracted from the students' dialogues, the research looked for highlighting the impact of the teacher in breaking stalemates in discussion with appropriate interventions. They explained the importance of collaborative group work in the development of students' CT skills. 
Halpern et al. (2012) explained that acquiring research acumen is a computerized learning game, which teaches CT and scientific reasoning and described it as an efficient method for helping educational systems. Popil (2011) investigated the use of case studies as teaching policies to promote CT and CT along with case studies were defined as teaching method. In their study, they reviewed related literature on how case studies could facilitate and promote active learning, help clinical problem solving, and encourage the development of CT skills. Piaw (2010) proposed a method to collect and provide information concerning the two thinking styles of the students. The method consisted of 34 items, which could be implemented to measure creative and CT style of the students, simultaneously.

Khandaghi et al. (2011) measured students' CT dispositions in humanities fields by randomly choosing 123 students from undergraduate students in the College of Humanities in Ferdowsi University of Mashhad, Iran during academic from 2010 to 2011. Their findings showed that all subjects achieved optimal level of CT in the moderated level $(p<0.001, t=17.56)$, but not in the strict level ( $p<0.001, t=-9.20)$. Ku and Ho (2010) examined the relative and combined impacts of thinking dispositions and cognitive ability on the CT performance of a group of 137 Chinese undergraduates. Their analysis indicated that only the disposition of concern for truth accounted for unique additional variance in CT beyond that explained by cognitive ability. Aizikovitsh and Amit (2010) studied the viability and consequences of developing CT among students through a program of instruction in probability, employing the infusion approach. An ANOVA test indicated that the experimental group substantially improved their CT capabilities and disposition.

\section{The role of religious educations}

Religious educations (RE) have recently become compulsory course materials in many countries where the rules and regulations are based on religion. There are literally increasing trend on the number of Middle East countries where people ask their governments to teach religious materials in schools. The recent changes in Arabian countries and change on the governments have created more opportunities to build more religious based schools, where people have the opportunities to learn more about their believes. In addition, the recent changes on technologies have created tremendous opportunities to help people learn more about ethical studies. Zarghami Hamrah (2011) investigated the impact of Internet in the religious education as the process in which belief, commitment, and worship-related, social and moral behaviors of the learner are formed and developed. Mirascieva et al. (2011) explained that in Western and secular culture, RE means a type of education, which is largely separated from academia. However, there are several European countries with some kind of religious education. They reported that the implementation of religious education in The Republic of Macedonia at present was considered through the subject Ethics in the religious in the primary school.

Genç et al. (2011) discussed the historical antecedents of the Turkish and Dutch educational system associated with religion(s) in education and explained different ways in RE in both countries. They also focused on the relationship between state and church and discussed how in both countries curricula and textbooks for religious education are built, checked and approved. Jaschok and Chan (2009) investigated the role of religious and secular education among Chinese Muslim women. According to their study, education was treated as a site where state and society were reproduced and/or challenged, where tensions arise over control of minds and bodies, and over interpretations and uses of religion and culture. Stolberg (2008) measured the behaviors to science and its association with religion of 92 pre-service primary teachers. Analysis of extended interviews with eight of the pre-service primary teachers demonstrated how specific religio-scientific structures could be linked to distinct changes in way to the teaching of religious education. 


\section{The relationship between $\mathrm{CT}$ and $\mathrm{RE}$}

We have already explained the relative importance of CT in increasing people's abilities to learn more but we have not yet mentioned how CT and RE could be integrated to provide more efficient and comprehensive guidelines for better exploring learning specially religious based studies. In fact, there are many common factors between these two issues as a combined method called CT-RE discussed in this section.

\subsection{CT-RE as searching for truth}

Human nature always look to find truth in the world using different methods and this is a common factor between CT and RE. In fact, many people salute human being's attempt for looking for truth. Once people are motivated to look for truth, we must expect CT among them since they start arguing different things and do not accept everything very easily.

\subsection{Precise vision}

When there is a criticize view in people's mind, people will have more perception on accepting true ideas. In many religious studies such as Islam, people are requested to carefully look in the world and think about the creator.

\subsection{Prevention of any bias and personal purposes}

According to religious studies, people are requested to be wise and prevent any bias decision, thinking about correct ways of reaching objectives and when the right ideas are against their will, simply accept them with open mind. People are strongly recommended to prevent any prejudgments.

\subsection{Flexibility and tolerance}

Flexibility and tolerance are two important characteristics of religious studies where people are asked to become flexible in society against people. This simple but sophisticated characteristic was the main reason for absorbing many people to some religions such as Islam. In fact, in holy book of Muslims, Quran, we repeatedly realize that if prophet Mohammad had not been able to tolerate people, they would have scattered in early stages of prophet Mohammad's mission.

\subsection{Being independent}

This is a fact that to criticize an idea people need to think independently and they should not be influenced from others.

\subsection{Clear judgment}

Any CT must be established based on some clear attributes and judgment needs to be accomplished solely based on crystal clear evidences.

\subsection{Fairness and respect to other views}

There are several evidences that religious studies suggest us to be fair with other people even if they do not agree with what we think. There was a case where the first Imam after prophet Mohammad had conflict of interest with a Jewish person and judge gave the right to Jewish person and despite the fact that Imam was the leader but he did not object. The moral story is that it is important to respect the other people's ideas. 


\subsection{Personal intention}

When people are criticizing ideas, they must have personal willing to look for truth and ideas. For instance, consider a person who cleans a clock and when he/she is asked on what time it is, the person will look one more time, which means when he/she was cleaning the clock, he/she did not pay attention on reading the time. The moral story is that when there is a critical thinking there must be a good intention on accepting new ideas as long as they are correct.

\subsection{Patience and hard working}

Any religious thinking must be accompanied with patience and hard working to yield a good result. In other word, any human being's achievement in the history was the results of hard working and no good result is achieved without good work.

In summary, we understand that critical thinking could be integrated with religious education in different levels and the we could benefit out of advantages of both concept.

\section{Conclusion}

In this paper, we have presented a literature review on recent studies on critical thinking and religious education. We have explained common factors between critical thinking and religious education and discussed that it is possible to take advantage of critical thinking on educating religious studies. The findings of this paper give insight on how religious studies could contribute to different educational studies. We have also discussed that a hybrid of CT and RE helps people search for truth, gives precise vision, helps use unbiased judgment, increases tolerance, helps become independent and create more transparent judgment, helps people have fair judgment and work harder.

\section{References}

Aizikovitsh, E., \& Amit, M. (2010). Evaluating an infusion approach to the teaching of critical thinking skills through mathematics. Procedia - Social and Behavioral Sciences, 2(2), 3818-3822.

Butler, H.A., Dwyer, C.P., Hogan, M.J., Franco, A., Rivas, S.F., Saiz, C., \& Almeida, L.S. (2012). The Halpern Critical Thinking Assessment and real-world outcomes: Cross-national applications. Thinking Skills and Creativity, 7(2), 112-121.

Çimer, A., \& Timuçin, M. (2010). Content of an in-service training to develop and assess activities minding critical thinking. Procedia - Social and Behavioral Sciences, 9, 958-962

Fung, D., \& Howe, C. (2012). Liberal Studies in Hong Kong: A new perspective on critical thinking through group work. Thinking Skills and Creativity, 7(2), 101-111.

Genç, M.F., Avest, I., \& Miedema, S. (2011). Religious education in two secular multicultural societies: The Turkish and Dutch case compared. Procedia - Social and Behavioral Sciences, 15, 801-805.

Glassner, A., \& Schwarz, B.B. (2007). What stands and develops between creative and critical thinking? Argumentation? Thinking Skills and Creativity, 2(1), 10-18.

Halpern, D.F., Millis, K., Graesser, A.C., Butler, H., Forsyth, C., \& Cai, Z. (2012).Operation ARA: A computerized learning game that teaches critical thinking and scientific reasoning. Thinking Skills and Creativity, 7(2), 93-100.

Jaschok, M., Chan, H.M.V. (2009). Education, gender and Islam in China: The place of religious education in challenging and sustaining 'undisputed traditions' among Chinese Muslim women. International Journal of Educational Development, 29(5), 487-494.

Khandaghi, M.A., Pakmehr, H., \& Amiri, E. (2011). The status of college students' critical thinking disposition in humanities. Procedia - Social and Behavioral Sciences, 15, 1866-1869 
Ku, K.Y.L. (2009). Assessing students' critical thinking performance: Urging for measurements using multi-response format. Thinking Skills and Creativity, 4(1), 70-76.

Ku, K.Y.L., \& Ho, I.T. (2010). Dispositional factors predicting Chinese students' critical thinking performance. Personality and Individual Differences, 48(1), 54-58

Marin, L.M., \& Halpern, D.F. (2011). Pedagogy for developing critical thinking in adolescents: Explicit instruction produces greatest gains. Thinking Skills and Creativity, 6(1), 1-13.

Mirascieva, S., Petrovski, V., \& Petrova Gjorgjeva, E. (2011). Teaching in the religious education in the Republic of Macedonia today. Procedia - Social and Behavioral Sciences, 15, 1404-1409

Piawa, C.Y.(2010). Building a test to assess creative and critical thinking simultaneously. Procedia Social and Behavioral Sciences, 2(2), 551-559

Popil, I. (2011). Promotion of critical thinking by using case studies as teaching method. Nurse Education Today, 31(2), 204-207

Renaud, R.D., \& Murray, H.G. (2008). A comparison of a subject-specific and a general measure of critical thinking. Thinking Skills and Creativity, 3(2), 85-93.

Stolberg, T.L. (2008). Understanding the approaches to the teaching of religious education of preservice primary teachers: The influence of religio-scientific frameworks. Teaching and Teacher Education, 24(1), 190-203

Stapleton, P. (2011). A survey of attitudes towards critical thinking among Hong Kong secondary school teachers: Implications for policy change. Thinking Skills and Creativity, 6(1), 14-23.

Zarghami Hamrah, S. (2011). Ontological investigation of the role of internet in religious education. Procedia - Social and Behavioral Sciences, 29, 1740-1749 